\title{
Chapter 20 \\ Are Individualist Accounts of Collective Responsibility Morally Deficient?
}

\author{
András Szigeti
}

\begin{abstract}
Individualists hold that moral responsibility can be ascribed to single human beings only. An important collectivist objection is that individualism is morally deficient because it leaves a normative residue. Without attributing responsibility to collectives there remains a "deficit in the accounting books" (Pettit). This collectivist strategy often uses judgment aggregation paradoxes to show that the collective can be responsible when no individual is. I argue that we do not need collectivism to handle such cases because the individualist analysis leaves no responsibility-deficit. Harm suffered in such situations can have only two sources. Harm is either due to culpable wrongdoing by individuals. Harm is then redressed by holding these individuals responsible. Or harm does not result from culpable wrongdoing. Such harm may have to be redressed too, but not because anyone is responsible for it. Therefore, the charge of moral insensitivity against individualist accounts can be rejected. Furthermore, in the last section of the chapter I will show that collectivist talk about moral responsibility can be used for ethically questionable purposes as well. Collectivists cannot claim the moral high ground.
\end{abstract}

\section{Introduction}

Individualism is here defined as the view that moral responsibility can be ascribed to single human beings only. In particular, no collective qua collective is a proper addressee of responsibility-ascriptions. More specifically, individualist accounts of collective responsibility hold that when we allocate responsibility for an outcome brought about by some group, we can either ascribe individual responsibility to

Work on this article was made in part possible by support from the Hungarian Innovation Office (formerly NKTH)/MAG Zrt. research project "What is it to be human?" (BETEGH 09).

\footnotetext{
A. Szigeti $(\bowtie)$

Department of Philosophy, Lund University, Lund, Sweden

e-mail: andras.szigeti@fil.lu.se
} 
individual members of that collective and/or ascribe joint responsibility to individual members for their contribution to the collectively brought about outcome. Once responsibility has been ascribed to individual members of the collective, however, there is nothing more to allocate in terms of backward-looking moral responsibility. ${ }^{1}$

Collectivism is the opposite view which holds that the responsibility of a group is in some cases not reducible to the responsibility of individual members of that group. In these cases, the collective qua collective is a proper addressee of responsibility-ascriptions.

The debate between individualists and collectivists about responsibility is being fought on two fronts. First, there is the theoretical clash concerning the nature of action and its metaphysical foundations. Thus some individualists doubt that collective responsibility is metaphysically possible believing that collective responsibility presupposes collective agency, but only individual human beings (if anybody) meet the conditions of agency. ${ }^{2}$

But, second, there is a normative, or more narrowly, ethical motivation to engage with the issue of collective responsibility as well. In late modernity it has become clearer than ever that the existence of collectives can crucially impact on human lives. By being associated with other people we become sources of special types of harm (and benefit) to others (Kutz 2000, pp. 1-3). It is hoped that getting a grasp on collective responsibility will enable us to place the blame (or praise) where it belongs. This ethical interest creates the second scene of battle between individualists and collectivists. Specifically, what many collectivists fear is that many familiar types of wrong (and good) happening to us may remain unaccounted for without a robust notion of collective responsibility.

The agent-theoretical and the ethical interests are obviously not independent from one another. ${ }^{3}$ Ultimately, what one is to think of the overall prospects of the

\footnotetext{
${ }^{1}$ It should be clear that the notion of responsibility I talk about here is robust, desert-based, backward-looking moral responsibility which is commonly thought to be presupposed by a distinct range of reactive attitudes (e.g., guilt, resentment, blame, etc.) and normative consequences (e.g., punishment, sanctions, reparation, etc.). Pettit, for example, makes it quite clear that this is the notion of responsibility he has in mind when talking about the responsibility of collective agents (see Pettit 2007, p. 174).

${ }^{2}$ Haji (2006), among others, shows how to run such an argument, although he stops short of drawing a definite anti-collectivist conclusion. See also Miller and Mäkelä (2005, p. 646n15) for such metaphysically-oriented anti-collectivist arguments. McKenna (2006) is an interesting mixed case. McKenna argues that while some collectives meet the conditions of agency, they do not meet the more exacting conditions of morally responsible agency. McKenna also adds (2006, p. 29) that his is an empirical claim and should not be taken to entail that as a matter of metaphysical impossibility there could not be morally responsible collective agents.

${ }^{3}$ For example, some believe that the (allegedly) unproblematic attributability of moral responsibility to collectives can be taken as evidence for the metaphysical possibility of collective agency. Or, conversely, some think that the metaphysics of collective agency is unproblematic, and since the metaphysics of collective agency is unproblematic, we have no reason not to acknowledge the attributability of moral responsibility to such collective agents (see French 1979). And then there are some who put forward independent but in their conclusions converging collectivist (or anticollectivist) arguments in both areas (e.g., Pettit 2007).
} 
opposing positions will depend on one's assessment of their respective contributions in both "theatres of war". In this chapter, however, I will focus only on the ethicallymotivated collectivist worry that individualism is morally deficient because it leaves a normative residue. Without attributing responsibility to collectives qua collectives, there remains a "deficit in the accounting books" (Pettit 2007, p. 194; see also French 1979, p. 207; Kutz 2000, p. 113; Copp 2006, p. 216, etc.). Nobody will be called to task for many kinds of harms, the source of which appears to be the existence of collectives-so especially (but not exclusively) for the harms brought on by corporations, governments, international organizations, and other organized collectives. Therefore, it is concluded, the individualist account is morally inferior to collectivist approaches.

I will argue in this chapter that there is no such responsibility-deficit. If harm ${ }^{4}$ is the result of culpable wrongdoing, it will be possible to account for it by ascribing responsibility to individuals. I will grant that there may be other types of harm suffered in the kind of situations the collectivist focuses on. It will become clear, however, that these other types of harm are not the result of culpable wrongdoing and so no responsibility can be ascribed for them. This is not to say that victims of these other types of harm can raise no legitimate claims for redress under certain circumstances. But if they can raise such claims, it is not because they have been the victims of culpable wrongdoing. In short, either some individual is responsible for the harms suffered or no one is. If that is correct, the charge of moral insensitivity levelled at individualist accounts can be rejected.

Further, as I will show at the end, collectivist talk about moral responsibility can be used for ethically questionable purposes as well. Collectivists cannot claim the moral high ground.

\section{Irreducible Collective Responsibility and Paradoxes of Judgment Aggregation}

The wrongs collectivists typically worry about are such that (i) they are brought about as a result of the actions of several individuals, and (ii) these individuals themselves do not appear to be culpable at all, or (iii) if even they are culpable to some extent, it is not clear that their culpability would add up to the sum total of culpability for the wrong which the given case involves, and finally, (iv) if the wrong in question had been done by an individual, we would not hesitate to hold that individual responsible (provided she is fit to be held responsible for that action of course, but that is another matter).

For example, each typical inhabitant of the metropolis upstream seems only marginally culpable for her contribution to polluting the river (after all, typically her contribution to pollution is neither necessary nor sufficient for the environmental

\footnotetext{
${ }^{4}$ In the following, I will only discuss responsibility-ascriptions for wrongdoing, setting aside the issue of praiseworthy actions.
} 
damage). Yet the pollution is a serious wrong suffered by the inhabitants of the village downstream. If the pollution had been brought about by a single individual, we would not hesitate to hold her responsible. But if there is no given individual to be held responsible for the pollution, should we just refrain from holding anyone responsible? Should we refrain despite the fact that the pollution is indisputably a collectively brought about outcome and so there is an obvious candidate for the ascription of responsibility, namely the collective itself?

There are different types of cases for which collectivist arguments have been made in this style: first, cases of collective omissions (Petersson 2008, etc.), second, cases of marginal individual contributions to collective harm (as in the pollution example above) (Kutz 2000, etc.), third, outcomes causally overdetermined by individual contributions (Kutz 2000, but cf. Parfit 1984), and fourth, cases which involve aggregations of individual judgments.

From here on, I will focus only on the fourth type of case here. I limit my inquiry to this type not only for reasons of space and not only because the most original collectivist arguments have been put forward in this area, but also because if the collectivist analysis of this fourth type of case is correct, collective-level responsibility for wrongdoing can be entirely autonomous from the responsibility of individual members of the collective. ${ }^{5}$ The collective can be culpable even if none of the members are. Therefore, the individualist could be guilty of creating a particularly large gap in the accounting books by not attributing responsibility directly to the collective. As a result, the argument from normative residue seems particularly forceful in this type of case.

As noted already, such cases involve complications of judgment aggregation. Here is my slightly modified version of a celebrated example (which was first introduced in Bovens and Rabinowicz 2006; see also List 2006; Copp 2006, 2007; Pettit 2007, etc.). ${ }^{6}$

\footnotetext{
${ }^{5}$ In the first three types of case, individual contributions may be said to be culpable to some extent because even if not necessary they constitute at least marginal contributions to the collectively brought about wrong or at least amount to some other sort of (non-causal) complicity in that wrong (see Kutz 2000). As we will see, no such complicity can be made out in the fourth type of case.

${ }^{6}$ Note that Bovens and Rabinowicz (2006) use the Tenure Committee example to focus on epistemic features of aggregation procedures. My version of the Tenure Committee case is probably closest to Copp (2007). However, it differs in important ways from how the case is presented there. In Copp's version of Tenure Committee, the committee's decision is taken in two stages, each of which involves a different decision procedure. The ground for complaint in Copp's version is that the respective outcomes of these two procedures conflict and the candidate is made aware of the results of both procedures. According to Copp, this two-stage decision raises a legitimate expectation in the candidate that she will receive tenure after the first stage which expectation is then frustrated after the second stage. But if this was the problem in the Tenure Committee case, then it could be easily fixed, namely by telling the candidate only about the final outcome after both stages have been concluded. If the collectivist argument is to get off the ground, then the Tenure Committee type case must involve some deeper flaw. I believe my version brings out what this deeper flaw may be, how it may serve as the basis for the collectivist argument, and why nevertheless that collectivist argument fails. I thank Kirk Ludwig for pressing me to make the difference between Copp's version and mine clearer.
} 
Table 20.1 Tenure Committee

\begin{tabular}{lllll}
\hline & Research? & Teaching? & Service? & Tenure? \\
\hline A & No (-p) & Yes (q) & Yes (r) & No -(p\&q\&r) \\
B & Yes (p) & No (-q) & Yes (r) & No -(p\&q\&r) \\
C & Yes (p) & Yes (q) & No (-r) & No -(p\&q\&r) \\
A\&B\&C & Yes (p) & Yes (q) & Yes (r) & Yes (p\&q\&r) \\
\hline
\end{tabular}

Three members of a university's tenure committee have to decide whether to award tenure to Ms Borderline. The university's standard for tenure states that excellence in the three areas of research, teaching, and service is required (and is sufficient) for tenure. In the case of Ms Borderline, in each of the three areas, a majority of the committee votes that she has achieved the required standard of excellence (i.e., the committee uses the so-called premise-based decision procedure). So they award tenure despite the fact that individually each member of the committee is against awarding tenure given that they each judge that Ms Borderline fails to meet one of the three required criteria (Table 20.1).

Now, the university administration or another candidate for tenure, call her Ms Secondbest, may challenge this result. The complaint appears to have some ground. After all, no member was in favor of awarding tenure! But who, if anyone, is responsible for the decision? Only the Tenure Committee as a whole can be responsible-after all, to repeat, no member was in favor of awarding tenure!

So let us retrace how the collectivist argument runs here. If the complaint is legitimate, then somebody must have wronged Ms Secondbest. But we can only charge the Tenure Committee with wronging Ms Secondbest. No individual member has done anything wrong. Furthermore, it is not simply that the members did not intend the collectively brought about outcome. Each member individually intended its opposite and cannot have foreseen the outcome! So they certainly cannot be charged with culpable wrongdoing.

But if only the Tenure Committee did wrong, then there will clearly be a responsibility-deficit unless we attribute responsibility to the collective directly. ${ }^{7}$ Moreover, attributing responsibility collectively to the Tenure Committee will eliminate the responsibility-deficit because the culpable wrongdoing at issue was done by the Tenure Committee, and the Tenure Committee only, i.e., not by the Committee's individual members or anyone else for that matter.

\footnotetext{
${ }^{7}$ Of course, as already noted, there are other necessary conditions for the attributability of moral responsibility. The addressee of the attribution must be fit to be held responsible. A number of conditions need to be met for this to be the case. In general, it is commonly thought that only agents are fit to be held responsible. So if collectives qua collectives are responsible, they must be agents qua collectives (see Copp 2006, pp. 216-7). Among others, Pettit argues that many groups meet these necessary conditions (Pettit 2003, 2007; Pettit and Schweikard 2006).
} 


\section{Some Individualist Responses Considered}

Let me repeat that I set aside here the various individualist objections which are based on the thought that collective responsibility presupposes collective agency, but collective agency is impossible for metaphysical reasons. I will just assume here for the sake of the argument that the collectivist can establish that the group is a rational agent in a sufficiently demanding sense, namely in the sense of satisfying the conditions that any agent has to satisfy in order to be fit to be held responsible. ${ }^{8}$

It is worth noting too that collectivists could also use the individualist's idea in reverse as it were, arguing that since Tenure Committee type cases show that there is robust collective responsibility, there must be robust collective agency too (see esp. Copp 2006, p. 216). So in any case, it is essential to evaluate the moral argument in favor of collectivism on its own merits.

As for ethical considerations, I think there is an individualist response to Tenure Committee type cases which should be rejected as well. This individualist response would be that if the Tenure Committee's actual decision is indeed morally objectionable, then this shows that the rule applied in the decision-making procedure is flawed, and so moral responsibility must lie with the individuals who adopted those rules in the first place.

This individualist response should be rejected. However, it should be rejected not because of what some collectivists say, which is that the rule-adopting individuals could not have foreseen the outcome and therefore have a legitimate excuse for adopting what in the end turned out to be a faulty rule (pace Copp 2007, p. 380). ${ }^{9}$ As will be seen shortly, even if the rule-adopting individuals could have foreseen the outcome, they could not have opted for a rule that was more likely to yield a better outcome. If blamed, they should plead lack of a better alternative, not ignorance. In short, this individualist response should be rejected for the right reason. This reason is that there is no alternative rule that would be in the relevant sense faultless (pace Miller 2007, p. 405). ${ }^{10}$

But in what sense exactly is the decision procedure flawed? The peculiarity of the decision in the Tenure Committee case as described above is that the decision

\footnotetext{
${ }^{8}$ As a matter of fact, I do not think that the collectivist can establish this. But that is a topic for another paper.

${ }^{9}$ Here is what Copp says in the passage referred to above: "Let me also stipulate that the Borderline case arose long before paradoxes and problems of voting procedures came to be widely known and to be studied in universities. Given these stipulations and given the familiar technical problems in designing voting procedures, it would be unreasonable to hold that someone in the university must be blameworthy for the faultiness of the university's rules." This collectivist argument misses the point about there not being less "faulty" alternative decision procedures available (this is probably due to the misleading presentation of the crucial example, see footnote 6 above).

${ }^{10}$ Miller's individualist response in (2007) to Copp fails, I think, precisely for this reason. If there is no alternative decision procedure available which would not be equally "flawed" in the relevant respect, then there cannot be a valid obligation, pro tanto or all-things-considered, to adopt another one, and so nobody is culpable or blameworthy for deciding in the way they have.
} 
reached is not supported individually by any of the members. As we have seen, it is on these grounds that Ms Secondbest could challenge the Tenure Committee's decision in that version of the case. The paradoxical result that the decision reached is not supported by any given committee member individually is indeed generated by the specific (premise-based) decision procedure used to aggregate the members' judgments in this particular case.

It is however not only the specific decision rule the Tenure Committee happened to use in the above case which yields such a paradoxical result. For example, the Tenure Committee could have an alternative rule in place whereby each member reaches her decision by individually considering each of the relevant criteria and each member votes only on one question, namely whether or not to award tenure to Ms Borderline (this is the so-called conclusion-based procedure). Since each member judges that Ms Borderline fails to meet one of the three required criteria, the Committee would not award the tenure to her.

But now Ms Borderline may challenge this result. After all, a majority of members judged that she did meet each of the required criteria! The problem is that there is decisive support in the Tenure Committee for both the decision objected to by Ms Secondbest and the decision objected to by Ms Borderline. ${ }^{11}$ Which will carry the day depends only on whether a conclusion-based or premise-based aggregation rule is used. If that is true, then there will always be a way to challenge the collective's decision. The result of the conclusion-based decision procedure can be challenged by appealing to the group's vote on individual criteria (the premises). The result of the premise-based procedure can be challenged by appealing to the aggregate of each member's individual judgment on whether to award tenure or not (the conclusion).

In fact, this problem is quite general and not restricted to the premise-based and conclusion-based procedures. We find a growing number of impossibility theorems for judgment aggregation in the literature. Common to these is the negative conclusion that there exists no aggregation procedure which could satisfy a limited and intuitive set of rationality criteria (provided the number of propositions to be decided upon and the number of group members is both larger than 2) (List and Pettit 2002). To put the same point in somewhat more technical terms, the paradox of collective judgment aggregation, as demonstrated in the pertaining impossibility theorems, consists in the fact that there exists no collective judgment aggregation procedure which for any (rational) profile of individual judgments will both (i) guarantee responsiveness to the views of members on each of the issues involved, and (ii) yield collective judgments on these issues which are themselves consistent and complete (List and Pettit 2002). This is why it cannot be guaranteed that for any distribution of judgments held by rational individual members of a group the respective outcomes of the premise-based and the conclusion-based procedures will be the same.

\footnotetext{
${ }^{11}$ In fact, the decision against Ms Borderline, the result of the conclusion-based procedure, would have unanimous support. But this difference is not what the collectivist is worried about, as we will see shortly.
} 
It is essential to keep in mind that the possibility of challenging the decision procedure, which the collectivist makes so much of, is based on this "flaw" rooted in the paradox of judgment aggregation. As already noted, several different versions of Tenure Committee can be found in the literature. The original version (Bovens and Rabinowicz 2006), for example, involves only two criteria of tenure to be voted upon. Because only two criteria are used, it will no longer be true that there is no overlap between any of the individual member's view and the final outcome of the premise-based procedure. By contrast, in my version, the outcome of the conclusion-based procedure is unanimously supported and so there will be no overlap between the collective view and that of the individual members. This difference, however, does not alter the basic structure of the paradox that creates the possibility of challenging the decision in both versions of Tenure Committee. It will still be true in the two-issue version too that the decision can be challenged because it cannot be guaranteed that the respective outcomes of the premise-based and the conclusion-based procedures are going to coincide.

\section{How the Individualist Should Really Respond}

Again, when assessing the collectivist argument we should not lose track of what the basis for the complaint is in cases such as Tenure Committee. In general, there are of course a great variety of other reasons why a decision taken in a collective by means of a formal decision procedure could be challenged or complained about. Let us consider some of these briefly in order to see that these are not the kinds of challenges the collectivist has in mind in cases of the Tenure Committee type.

The basis for one important type of complaint is that the decision procedure was substantially unfair, i.e., that for some reason the playing field was not level. And, no doubt, procedures for decision-making can be faulted for substantial deficiencies in many cases: personal bias, prejudice, sloppiness, failure to consider all the relevant facts can all skew decisions taken by a group. In such cases, ascriptions of individual responsibility may be apposite. The wrong involved in adopting a faulty decision procedure in such cases is indeed due to culpable wrongdoing by one or more individuals, e.g., those who opted for the faulty decision procedure, say, in the hope of personal gain. Holding these individuals responsible-and consequent upon the ascription of responsibility, punishing them, criticizing them, calling upon them to apologize or make reparation or whatever response seems appropriate in the given situation-is the way to redress the harm caused in such cases.

But, of course, such substantial unfairness is not what the collectivist argument under scrutiny builds upon. The collectivist's problem is not that the playing field would not be level in Tenure Committee type cases.

There can also be other, more subtle epistemic and moral reasons to challenge a given decision procedure used for aggregating judgments as well. Specifically, it 
may be argued on the basis of various epistemic or moral criteria that the premisebased and conclusion-based procedures are not equally suitable for the aggregation of judgments. This may be due to the particular circumstances of situations in which judgments have to be aggregated and/or due to general differences between the two decision procedures. ${ }^{12}$

For example, it has been argued that the premise-based procedure is under most circumstances a better "truth-tracker" than the conclusion-based procedure (Pettit and Rabinowicz 2001; Bovens and Rabinowicz 2006). It has also been argued that the premise-based procedure could be preferable for moral and political reasons as well. Thus it is said that only if the group votes on each of the premises will all the reasons for taking a given decision be publicly accessible and contestable (Pettit 2001).

The premise-based procedure is often thought to be preferable if time is also a relevant consideration. The claim here is that the premise-based procedure enables the collective to preserve a stable identity and pursue common goals over time as earlier interconnected decisions of a group are in this procedure regarded as premises of the proposition to be decided upon at a later time. By contrast, the conclusion-based procedure could generate inconsistencies at the collective level because each decision is voted upon according to members' views on the given issue, irrespective of the fact that this decision may potentially conflict with the conclusion that earlier judgments of the same group would logically entail (Pettit 2001, 2007).

At the same time, there are other considerations favoring the conclusion-based procedure. First, in some cases groups may want to put a premium on unanimity over simple majority. Thus notice that the conclusion-based procedure in the Tenure Committee case yields a unanimously supported decision, whereas in the premisebased procedure the aggregation of each judgment (whether $p$, whether $q$, etc.) is supported only by a majority. Ceteris paribus, some may regard this difference as a reason for preferring the conclusion-based procedure. Second, the conclusion-based procedure may better safeguard against unwanted strategic voting. Third, although the premise-based procedure is under most circumstances a better "truth-tracker" as mentioned above, this is not always the case (for details, see Bovens and Rabinowicz 2006). Fourth, in some cases we may want to or have to take a stand on a logically complex proposition as a whole without having a firm view on one or more of the simple propositions constituting it. The conclusion-based procedure can better accommodate such situations.

Whatever the respective merits of the premise-based and conclusion-based procedures may be in terms of these epistemic, moral, and political desiderata, however, the point to emphasize here is that these relative advantages are irrelevant

\footnotetext{
${ }^{12}$ I am indebted to Wlodek Rabinowicz for calling my attention to such alternative criteria for assessing the relative merits of the premise-based and conclusion-based decision procedures.
} 
to the case at hand. The collectivist argument discussed here is based on the paradox of judgment aggregation, i.e., the inevitable conflict between the outcomes of the premise-based and conclusion-based procedures. ${ }^{13}$

I believe that the right individualist response should focus precisely on the unavoidability of the conflict. There is no procedure that can guarantee outcomes against which nobody can raise a legitimate complaint (List and Pettit 2002; List 2006, p. 376). If that is true, what basis is there to judge the collective culpable? What exactly is the collective collectively responsible for?

For the sake of argument, let us assume that members of the Tenure Committee were aware of the possibility of ending up straddled with the kind of paradoxical results discussed above. Still, when deliberating about the issue, there will not be an option available to the members against which no complaint could be raised. Therefore, it would follow that all options open to the Tenure Committee were culpable. But we are reluctant to hold agents responsible if every course of action available to them is equally culpable. ${ }^{14}$

The right individualist response therefore is to say that in such cases there is simply nobody to be held responsible, nobody culpable, and nobody to be blamed for these paradoxical results: neither one or more individuals nor some collective as a whole. $^{15}$ In other words, it is a mistake to take the paradoxical outcome as evidence for the occurrence of culpable wrongdoing in Tenure Committee type cases

\footnotetext{
${ }^{13}$ Collectivist authors are not always as clear on this point as one would wish them to be. Sometimes they do not really explain why they think one would have a reason to challenge the decision resulting from the aggregation of judgments. For example, discussing an example of the same structure as Tenure Committee, Pettit (2007, p. 198) only says this: "But suppose now that some external parties have a complaint against the group ... because [they] think [the collective's decision] is unfair." But he does not specify what the reason for the complaint here would be. Is it some substantial unfairness of the kind I have discussed above? That cannot be the case because the playing field was level. Is the decision challenged as unfair because a decision procedure was used which is inferior in terms of the epistemic, moral, or political criteria mentioned above? No. In fact, in this particular case Pettit allows that the collective decision be legitimately challenged, even though this group opts for the premise-based procedure which Pettit tends to describe in various places as by and large preferable in terms of the epistemic, moral, or political desiderata just discussed. To be fair, elsewhere (e.g., Pettit 2001), Pettit is much clearer about what he holds to be the truly relevant reason for the "challengeability" of the collective decision emphasizing that Tenure Committee type cases present a dilemma. These cases are dilemmatic because none of the available decision procedures is immune to challenges given the paradox of judgment aggregation. ${ }^{14}$ From the metaphysical point of view, there is an additional problem. The retort implies that the collective adopted the procedure at some point and so it implies that the collective acted. But the procedure was adopted by one or more individuals, not the collective.

${ }^{15}$ The collectivist can object that by accepting this claim the individualist will increase the responsibility-deficit—now in a different way than before. If it were true that nobody was to be held responsible for paradoxical outcomes of judgment-aggregation, then this would create a "perverse incentive." This is because people could now form collectives "to achieve a certain bad and selfserving effect, while arranging things so that none of them can be held fully responsible for what is done" (Pettit 2007, p. 196). But this objection is confused. If people deliberately arranged things in order that the aggregation of their judgments yielded such paradoxical results and hoped thereby to evade responsibility, then they would of course be individually culpable for doing so.
} 
by any individual or collective. On second thoughts, this is not all that surprising: it is nobody's fault, not any individual's nor that of any given collective, that judgment aggregation is fraught with paradox. That is just the way the world is.

\section{Harm without Responsibility}

If this is correct so far, should we then not say also that nobody has been wronged in this case? I think this does not follow. In my view, there is indeed something wrong with the fact that Ms Borderline's tenure can depend solely on whether the Tenure Committee members' views are aggregated via the premises or via the conclusion.

Not all individualists agree. Some would question whether there is any valid claim for redress in Tenure Committee type situations. Why should the fact that the outcome depends on the decision procedure in the way described above constitute a legitimate reason for complaint by anyone as long as the playing field was level? - they ask. After all, the result also depended on the fact that the Committee happened to consist of three and not two or four members. By the same logic, would that dependence not be a legitimate reason for challenging the decision too? If all such procedural factors could constitute a reason for complaint, then no decision could ever be taken. What is crucial, according to these individualists, is that both the premise-based and the conclusion-based procedures are reasonable, impartial and procedurally fair-the playing field is level. If so, then there is no room for challenges on the basis that some alternative decision procedure would have produced a different result. ${ }^{16}$

Let me point out first of all that this argument of course would only strengthen the anti-collectivist position I have been defending. But I think it goes too far. We can see where it goes too far if we focus on the question what the content of the complaint in the Tenure Committee type case could be. If, say, the conclusion-based procedure is used and Ms Borderline is denied tenure as a result, her complaint should not be that the result of the conclusion-based procedure was unjustified. That complaint would not be legitimate since, as noted, the playing field was level and the procedure used reasonable, impartial, etc. Rather, her complaint should be that the reason why she was ultimately denied tenure was extraneous to her qualifications for the position. It was extraneous in the same way as flipping a coin to break a tie may be in other situations. Of course, in many cases the dependence of the decision on such extraneous factors does not make a decision unjustified. Sometimes we do need to flip a coin if the matter at hand is to be decided one way or another. By the same token, sometimes either the premise-based or the conclusion-based procedure will have to be used and we cannot use both. We cannot have our cake and eat it.

\footnotetext{
${ }^{16}$ I owe this point to Kirk Ludwig.
} 
And yet, that the outcome can be traced back to such an extraneous factor can sometimes be, to borrow Feinberg's idea, unjust even if justified. ${ }^{17}$ Furthermore, I believe that in some cases that sort of injustice does constitute a legitimate basis for a redress claim. What form the compensatory action should take, if any, will depend on the circumstances of the case. In Tenure Committee, it could be argued that the inconsistency between the outcome of the premise-based and conclusionbased procedures can constitute a reason for some compensatory action. The range of options include repeating the procedure by adding further criteria, or including more people in the Committee, or (if the conclusion-based procedure was used) giving Ms Borderline another chance a year later, or (if the premise-based procedure was used) creating a tenure position for Ms Secondbest as well, and so on. ${ }^{18}$

Given the exigencies of situations in which similar decisions have to be taken, such compensatory action is not always possible. Nor would I want to claim here that paradoxical outcomes of judgment aggregation constitute a sufficient reason for compensatory actions of this sort. The point is simply that such paradoxical outcomes do sometimes constitute a legitimate basis for a redress claim and may constitute $a$ reason for satisfying such a claim.

I believe that this individualist analysis of the Tenure Committee example generalizes for all cases in which some harm or disadvantage is suffered due to paradoxical results of judgment aggregation. Individualism denies that such cases warrant ascriptions of responsibility to collectives. But this does not entail that individualism is morally inferior to collectivism. In fact, individualists accept that paradoxes of judgment aggregation can give rise to legitimate complaints and so can require compensatory action. What individualists deny is that the normative basis for these complaints is the ascription of collective responsibility.

\footnotetext{
17 " $[\mathrm{O}]$ ne and the same act can be both unjust (to someone or other) and justified" (Feinberg 1970, p. 45).

${ }^{18} \mathrm{An}$ anonymous referee pointed out that by insisting that members of the Tenure Committee qua committee members should care about redressing the unjust consequences of the decision taken, I acknowledge in effect that members of the Tenure Committee can regard themselves as individually responsible (even if not culpable) for how they voted and participated in the collective decision. In fact, it may be said to follow from what I am saying above that members can even feel collectively responsible, if only in an attenuated sense, since I urge that they as members of the Tenure Committee should address the complaint and do something about it if all possible. I have no problem with these implications provided we remain clear about what is meant by "feeling collectively responsible". First, the fact that individual members are not culpable for the outcome does not mean that they cannot be required to alleviate the harmful effects of that outcome. We can often be required to redress harms for which we are not morally responsible (sometimes not even causally responsible). Such a requirement often has to do with our roles as members of organized groups or institutions. Furthermore, in some cases, redressing harms (whether or not one is morally responsible for that harm in the first place) requires cooperation with others as when I need you so that we can lift that stretcher together. Second and relatedly, it is also true that members should be individually concerned about how their individual contributions combine with those of others (and may be held individually responsible if they fail to do so) especially if those contributions, although severally harmless, have harmful effects in the aggregate. But of course all these considerations pertain to individual responsibility and do not imply collective responsibility of the kind the collectivist would want to establish.
} 


\section{The Moral High Ground}

Tenure Committee type cases have also been used to make ambitious collectivist claims about the personhood of collectives. After all, in one version of Tenure Committee nobody except the collective as a whole judges Ms Borderline to be deserving of tenure. If groups can abstract from the views of their members in this way, collectivists claim, they can have their own irreducibly collective values, intentions, beliefs, and judgments. It follows that we may have to regard them as fully enfranchised members of the moral community together with natural persons. As noted, the collectivist thinks that this is a good thing from the ethical point of view because this allows us to call to task collective persons in the same way as natural persons (French 1979, p. 207; Pettit 2003, p. 184). Corporations, governments, international organizations can no longer claim to be merely a piece of legal fiction when facing moral criticism, blame, or sanctions.

I have put forward some arguments against this line of thought above. In closing, I want to offer an example to illustrate that enfranchising collectives with a status resembling that of natural persons can raise as many ethical problems as it may solve. In a recent landmark decision, Citizens United v. Federal Election Commission, the US Supreme Court lifted the ban on corporate funding of political advertising. The Supreme Court's main argument for this extremely controversial ruling was precisely that the interests of corporations are to be treated on a par with those of natural persons (Dworkin 2010).

This shows that "collectivist" talk concerning the personhood of collectives can also serve to increase the power of collectives rather than limit it. Most would agree that, even if it were legally defensible, increasing the power of collectives in the way the Supreme Court has done in this case is hardly desirable morally speaking. It is objectionable because given the infinitely richer resources which corporations have access to they acquire an enormous advantage in the competition to influence the opinions of the electorate. This advantage is not only unfair in itself, it also restricts the freedom of speech of others.

Of course, collectivists need not agree with the Supreme Court's decision in this case. They may continue to distinguish between the rights of natural as opposed to organizational persons despite their readiness to attribute responsibility to collectives qua collectives. So in this specific case, they may draw a line between natural and organizational persons in terms of the right to free speech. ${ }^{19}$ But if this is the position the collectivist wishes to defend, then the individualist can rightly demand additional arguments from the collectivist why we should not distinguish between natural and organizational persons in terms of responsibility (and other attributes of personhood) even though we treat them differently in terms of the rights they enjoy, or at least differently in terms of some of the specific basic rights they enjoy.

\footnotetext{
${ }^{19}$ I thank Christian List for alerting me to this possible collectivist rejoinder.
} 
In the bulk of this essay, I have sought to defend individualism against a specific collectivist charge. This last section constitutes an attempt to turn the tables and go on the offensive as it were. A single example is of course insufficient to support such an attack on collectivism. It does give us reason, however, to recognize the possibility that in some cases the collectivist rhetoric may actually create moral deficits which individualism can easily steer clear of.

\section{References}

Bovens, L., and W. Rabinowicz. 2006. Democratic answers to complex questions-An epistemic perspective. Synthese 150(1): 131-153.

Copp, D. 2006. On the agency of certain collective entities: An argument from normative autonomy. Midwest Studies in Philosophy 30: 194-221.

Copp, D. 2007. The collective moral autonomy thesis. Journal of Social Philosophy 38(3): 369-388.

Dworkin, R. 2010. The devastating decision. New York Review of Books 57(8): 63-67.

Feinberg, J. 1970. Doing and deserving. Princeton: Princeton University Press.

French, P. 1979. The corporation as a moral person. American Philosophical Quarterly 16(3): 207-215.

Haji, I. 2006. On the ultimate responsibility of collectives. Midwest Studies in Philosophy 30: 292-308.

Kutz, C. 2000. Complicity. Cambridge: Cambridge University Press.

List, C. 2006. The discursive dilemma and public reason. Ethics 116(2): 362-402.

List, C., and P. Pettit. 2002. The aggregation of sets of judgments: An impossibility result. Economics and Philosophy 18(1): 89-110.

McKenna, M. 2006. Collective responsibility and an agent meaning theory. Midwest Studies in Philosophy 30: 16-34.

Miller, S. 2007. Against the collective moral autonomy thesis. Journal of Social Philosophy 38(3): 389-409.

Miller, S., and P. Mäkelä. 2005. The collectivist approach to collective moral responsibility. Metaphilosophy 36(5): 634-651.

Parfit, D. 1984. Reasons and persons. Oxford: Oxford University Press.

Petersson, B. 2008. Collective omissions and responsibility. Philosophical Papers 37(2): 243-261.

Pettit, P. 2001. Deliberative democracy and the discursive dilemma. Philosophical Issues 11(1): 268-295.

Pettit, P. 2003. Groups with minds of their own. In Socializing metaphysics, ed. F. Schmitt, 167-194. New York: Rowman \& Littlefield.

Pettit, P. 2007. Responsibility incorporated. Ethics 117(2): 171-201.

Pettit, P., and W. Rabinowicz. 2001. The jury theorem and the discursive dilemma. Philosophical Issues 11(1): 295-299.

Pettit, P., and D. Schweikard. 2006. Joint action and group agency. Philosophy of the Social Sciences 36(1): 18-39. 